\title{
Targeting of cholecystokinin $\mathrm{B} /$ gastrin receptor in colonic, pancreatic and hepatocellular carcinoma cell lines
}

\author{
KAY SAVAGE $^{1}$, H. ANNE WALLER ${ }^{1}$, MARK STUBBS ${ }^{1}$, KORSA KHAN $^{1}$, SUSAN A.WATSON ${ }^{2}$, \\ PHILIP A. CLARKE ${ }^{2}$, STEVE GRIMES ${ }^{3}$, DOV MICHAELI ${ }^{3}$, AMAR P. DHILLON $^{1}$ and MARTYN E. CAPLIN ${ }^{4}$ \\ ${ }^{1}$ Department of Histopathology, Royal Free Hospital, Pond Street, Hampstead, London NW3 2QG; ${ }^{2}$ Academic Unit of Cancer \\ Studies, Queens Medical Centre, University of Nottingham, Nottingham NG7 2UH, UK; ${ }^{3}$ Aphton Corporation, Woodland, \\ California, USA; ${ }^{4}$ Department of Medicine, Royal Free Hospital, Pond Street, Hampstead, London NW3 2QG, UK
}

Received July 3, 2006; Accepted August 29, 2006

\begin{abstract}
Gastrin is a growth factor for both gastrointestinal and non-gastrointestinal tumours. Endocytosis of gastrin has been demonstrated in tumour cell lines expressing cholecystokinin-B/gastrin receptor (CCK-BR); this has raised the possibility of receptor targeted therapy. The aim of this study was to examine endocytosis of gastrin and CCK-BR in tumour cell lines. A small gastrin analogue, RG-G7, and the anti-CCK-BR antibody, anti-GRE1, were fluorescently labelled and uptake by cancer cell lines including AR42J, HepG2, and C170HM2 as well as transfected NIH3T3 fibroblast cells was assessed using standard and confocal fluorescence microscopy. CCK-BR expression of cell lines was assayed by reverse transcription-polymerase chain reaction and Western blotting. Apoptosis was detected using a fluorescent TUNEL method. RG-G7 and anti-GRE1 antibody were specifically taken up by all cell lines expressing CCK-BR. In addition to cytoplasmic uptake with RG-G7 and anti-GRE1 the latter also showed specific uptake into the nucleus. A coincidence of anti-GRE1 and apoptosis was seen. Targeting CCK-BR by peptide or antibody may offer therapeutic opportunities for some cancers.
\end{abstract}

\section{Introduction}

Gastrin is a peptide hormone which has long been known as a stimulant of gastric acid secretion (1). It also exerts a trophic effect on normal and malignant gastrointestinal cells both in vitro and in vivo (2-7), and can act as a growth factor for some non-GI tumours $(8,9)$. In the post-translational processing of gastrin the precursor form preprogastrin is cleaved by enzymes to produce progastrin and by further

Correspondence to: Dr M.E. Caplin, Department of Medicine, Royal Free Hospital, Pond Street, Hampstead, London NW3 2QG, UK

E-mail: m.caplin@medsch.ucl.ac.uk

Key words: CCK-BR, gastrin, immunocytochemistry, cancer, immunotherapy enzymic cleavage to glycine-extended gastrin and finally the mature amidated gastrin (10). Amidated gastrin exerts its effect via the cholecystokinin (CCK)-B/gastrin receptor, a G-protein coupled receptor with seven hydrophobic transmembrane domains (11). There are two types of CCK receptors, type A and type $\mathrm{B}$. CCK-A receptor was first characterised on pancreatic acinar cells (12), and CCK-B receptor was initially characterised in the brain (13), and has subsequently been shown to be identical to the gastrin receptor $(11,14,15)$. The CCK-A and -B receptors show $48 \%$ amino acid homology (16), and can be differentiated by their agonist binding. CCK-A receptor binds sulphated CCK8 with high affinity and gastrin with low affinity, whereas CCK-B receptor (CCK-BR) recognises gastrin and both sulphated and non-sulphated CCK8 with approximately equal affinity (17). CCK-B/gastrin receptors are expressed in a number of human neoplastic cell lines and tissues of GI and non-GI origin (18-26).

Our group has been studying the expression of CCK-B/ gastrin receptor in a number of tumours, using an anti-gastrin receptor antibody (anti-GRE1 antibody). We have previously demonstrated in addition to membrane and cytoplasmic expression of CCK-BR that there is nuclear expression of the receptor in some cancers including hepatocellular and pancreatic carcinoma (27-29). These studies were principally performed using immunocytochemistry and immuno-electron microscopy.

The aim of this study was to examine with confocal microscopy endocytosis of gastrin and CCK-B/gastrin receptor, using the anti-CCK-BR antibody, anti-GRE1. A fluorescently labelled anti-gastrin receptor antibody (anti-GRE1) and gastrin peptide derivative (RG-G7) (30) were used to observe co-localisation of gastrin and gastrin receptor, and uptake of the anti-receptor antibody by tumour cells. The secondary aim was to determine the difference between uptake of antibody and of RG-G7 which may be of practical importance in the consideration of targeted therapy using antibody versus peptide. The studies were performed on cancer cell lines of colonic, pancreatic and hepatic origin (31-33), as well as on a mouse fibroblast cell line NIH3T3. NIH3T3 cells, transfected with either a classical or spliced variant of CCK-BR, were used as a positive control (34). Sub-cellular localisation was determined using confocal scanning laser microscopy (CSLM). 


\section{Materials and methods}

Gastrin and anti-gastrin receptor antibody. Gastrin-7 (Sigma, Poole, Dorset, UK) was labelled with rhodol green (RG-G7) according to the method of Czerwinski et al (35). This short form of labelled gastrin has previously been shown to react specifically with the CCK-B/gastrin receptor whilst retaining the biological properties of gastrin (30).

Anti-GRE1 is an affinity purified rabbit polyclonal antibody targeting the amino terminal extra-cellular domain of human CCK-BR, raised using a peptide consisting of residues 5-21 of the CCK-B/gastrin receptor as previously described (29). The specificity of this antibody for the CCK-B/gastrin receptor has been confirmed by Western blotting, ELISA and radioligand inhibition binding studies (29). Anti-GRE1 antibody (Aphton, CA, USA) was labelled with a red fluorescent marker (Alexa-546; Molecular Probes, OR, USA). This label was chosen because it is more fluorescent and more photostable than other commonly used markers (36), and is particularly suitable for confocal fluorescence microscopy. Briefly, the antibody was concentrated by centrifugation using centriconSR3 vials (Amicon, MA, USA) to a final concentration of $2 \mathrm{mg} / \mathrm{ml}$. Antibody $(0.5 \mathrm{ml})$ was added to a vial of dye, mixed, and incubated overnight at $4^{\circ} \mathrm{C}$, then labelled antibody was separated from unincorporated dye using a gel column. The staining characteristics of the fluorescently labelled antibody were compared to those of unlabelled antibody by staining of formalin fixed, paraffin embedded material from a gastrinoma. Binding of unlabelled antibody was detected using alkaline phosphatase conjugated sheep anti-rabbit antibody (Sigma). Specificity of binding of Alexa 546-labelled anti-GRE1 antibody was confirmed by preabsorbtion of antibody with antigenic peptide. $\mathrm{F}(\mathrm{ab})$ and $\mathrm{F}(\mathrm{ab})_{2}$ fragments of anti-GRE1 antibody were labelled with rhodamine, using standard techniques (37). The staining characteristics of these fragments of GRE1 antibody were confirmed in the same way.

Tumour cell lines. Tumour cell lines studied included AR42J, a rat pancreatic acinar carcinoma cell line (31); HepG2, a human hepatoma cell line (32); and C170HM2, a human colonic carcinoma cell line (33). For a positive control, NIH3T3 cells stably transfected with expression vector containing either the classical or spliced variant form of the human CCK-B/gastrin receptor cDNA were used (34). Non-transfected NIH3T3 cells were used as a negative control. AR42J, HepG2 and NIH3T3 cell lines were obtained from the European collection of cell cultures (ECACC, Porton Down, UK); C170HM2, a recombinant colon cancer cell line, was from University of Nottingham, UK; transfected NIH3T3 cells were a gift from Professor T. Matsui (Kobe University, Kobe, Japan).

AR42J, C170HM2, HepG2 and non-transfected NIH3T3 cells were grown in RPMI-1640 medium containing $10 \%$ foetal calf serum and $2 \mathrm{mM}$ glutamine (Sigma). Transfected NIH3T3 cells were grown in the same medium plus Geneticin ( $1 \mathrm{mg} / \mathrm{ml}$; Sigma) to select for clones expressing the plasmid.

Uptake of $R G-G 7$. Cells were grown to $80 \%$ confluency at $37^{\circ} \mathrm{C}$ in $5 \% \mathrm{CO}_{2}$ in air at $100 \%$ humidity. Cells were seeded onto glass four-well slides (Beckton-Dickinson, NJ, USA) in phenol red-free medium, and again grown to $\sim 80 \%$ confluency. RG-G7 was added at a concentration of $50 \mathrm{nM}$ for $1 \mathrm{~h}$ at $37^{\circ} \mathrm{C}$. Cells were then rinsed in $0.01 \mathrm{M}$ phosphate buffer containing $0.0027 \mathrm{M} \mathrm{KCl}$ and $0.137 \mathrm{M} \mathrm{NaCl}, \mathrm{pH} 7.4$ (PBS), fixed for $5 \mathrm{~min}$ in $10 \%$ neutral buffered formalin, rinsed again in PBS and then mounted in Vectashield (Vector, CA, USA).

To demonstrate any membrane binding of RG-G7, cells were incubated with Alexa-594 conjugated concanavlin A (Molecular Probes) for $3 \mathrm{~min}$ at $4^{\circ} \mathrm{C}$ before fixation. Results were viewed using both standard and confocal fluorescence microscopy. Fluorescent staining of cells was visualised on a Zeiss standard 14 epifluorescence microscope with an HBO $50 \mathrm{~W}$ high pressure mercury source and Zeiss filter set no. 9. Confocal laser scanning was performed using an Olympus BH2 microscope with a Bio-Rad (Hemel Hempsted, UK) MRC 600 confocal laser imaging system with an Argonkrypton laser, and COMOS 7.0A image acquisition software.

Co-localization of gastrin and gastrin receptor. After incubation with RG-G7 for $1 \mathrm{~h}$, AR42J cells were fixed, then incubated with Alexa-546 conjugated anti-GRE1 antibody (20 $\mu \mathrm{g} / \mathrm{ml}$ in PBS) for $1 \mathrm{~h}$ at room temperature. Slides were then rinsed in PBS for $5 \mathrm{~min}$, mounted, and viewed by standard and confocal fluorescence microscopy.

Uptake of anti-CCK-B/gastrin receptor antibody (anti-GRE1 antibody). Cells were grown onto glass four-well slides as for RG-G7. Alexa-546 conjugated anti-GRE1 antibody was added to the cells for $1 \mathrm{~h}$ at $37^{\circ} \mathrm{C}$ at a concentration of $20 \mu \mathrm{g} / \mathrm{ml}$. Cells were rinsed in PBS, then fixed in formalin and mounted in Vectashield (Vector). Anti-GRE1 antibody was added to tumour cell lines (described above) and to transfected and non-transfected NIH3T3 cells. Rhodamine-labelled F(ab) and $\mathrm{F}(\mathrm{ab})_{2}$ fragments of anti-GRE1 antibody were also added to all cell lines, under the same conditions. As a negative control, rhodamine-conjugated rabbit anti-mouse immunoglobulin (Dako), and rhodamine-conjugated rabbit IgG, $\mathrm{F}(\mathrm{ab})_{2}$ fragment (Jackson Immunoresearch Labs, PA, USA) were added to cell lines at the same concentration $(20 \mu \mathrm{g} / \mathrm{ml})$ as anti-GRE1 antibody, for $1 \mathrm{~h}$ at $37^{\circ} \mathrm{C}$.

Detection of apoptosis. GRE1 antibody was added to all cell lines as described above. After incubating for $1 \mathrm{~h}$ at $37^{\circ} \mathrm{C}$, cells were rinsed in PBS and fixed in 1\% paraformaldehyde/ PBS (Sigma). Apoptotic cells were detected using the TUNEL method (Apoptag fluorescein in situ detection kit, Intergen, USA), according to the manufacturer's instructions.

Immunoblotting. Lysates of all cell lines were prepared in $80 \mathrm{mM}$ Tris buffer pH 6.8 containing 5\% sodium dodecyl sulphate and $1 \mathrm{mM}$ phenylmethyl-sulphonyl fluoride (Sigma). Protein content in the lysates was measured using a modified Lowry assay (Bio-Rad).

A volume of lysate corresponding to $10 \mu \mathrm{g}$ total protein from each sample was loaded onto a $10 \%$ acrylamide gel (Sigma). After separation, the proteins were electrotransferred to nitrocellulose membranes (Bio-Rad).

The membranes were incubated in PBS containing 5\% bovine serum albumin/0.1\% Tween-20 (Sigma) for $1 \mathrm{~h}$ at room temperature followed by 2 -h incubation with the same 
Table I. Detailing uptake of RG-G7 peptide and anti-GRE1 antibody (and fragments) into cell compartments by cell lines.

\begin{tabular}{|c|c|c|c|c|c|c|c|c|c|c|c|c|c|c|c|}
\hline & \multicolumn{3}{|c|}{ AR42J } & \multicolumn{3}{|c|}{ C170HM2 } & \multicolumn{3}{|c|}{ HepG2 } & \multicolumn{3}{|c|}{$\begin{array}{c}\text { NIH3T3 } \\
\text { (transfected) }\end{array}$} & \multicolumn{3}{|c|}{$\begin{array}{c}\text { NIH3T3 } \\
\text { (non-transfected) }\end{array}$} \\
\hline & $\mathrm{m}$ & $\mathrm{c}$ & $\mathrm{n}$ & $\mathrm{m}$ & $\mathrm{c}$ & $\mathrm{n}$ & $\mathrm{m}$ & $\mathrm{c}$ & $\mathrm{n}$ & $\mathrm{m}$ & c & $\mathrm{n}$ & $\mathrm{m}$ & $\mathrm{c}$ & $\mathrm{n}$ \\
\hline GRE1 & + & + & + & + & + & + & + & + & + & + & - & - & - & - & - \\
\hline Fab1 & + & + & + & + & + & + & + & + & + & + & - & - & - & - & - \\
\hline Fab2 & + & + & + & + & + & + & + & + & + & + & - & - & - & - & - \\
\hline RG-G7 & + & + & - & + & + & - & + & + & - & + & - & - & - & - & - \\
\hline
\end{tabular}

m, membrane; c, cytoplasmic; $n$, nuclear

buffer containing either anti-GRE1 antibody (1:200) or antiGRE1 preabsorbed with the antigenic peptide. The membranes were washed with PBS/0.1\% Tween-20 and incubated with biotinylated goat anti-rabbit/mouse antibody (Dako; 1:200) in $0.1 \%$ Tween-20/PBS for $1 \mathrm{~h}$. After washing with PBS, the membranes were incubated with streptavidin-biotin complex (Dako) for $1 \mathrm{~h}$. Labelling was revealed using diaminobenzidine (Vector).

Detection of gastrin receptor $m R N A$. To detect expression of $\mathrm{CCK}-\mathrm{B} /$ gastrin receptor in these cell lines, reverse transcriptionpolymerase chain reaction (RT-PCR) was performed to detect CCK-B/gastrin receptor mRNA. Total RNA was isolated from all cell lines. Cell suspensions were prepared using trypsinEDTA, and total RNA isolated from $1-3 \times 10^{6}$ cells using the $\mathrm{SV}$ total RNA isolation system (Promega) according to the manufacturer's directions. DNAase I digestion was performed to reduce the possibility of amplification of genomic sequences. Yields were estimated by UV spectrophotometry and RNA integrity was confirmed using denaturing gel electrophoresis. Reverse transcription and PCR were carried out using the one-step Access RT-PCR system (Promega). Specific primers for both gastrin receptor (19) and $\beta$-actin (24) were used; these span introns enabling the distinction of genomic and mRNA amplimers.

RT-PCR was performed on 1-2 $\mu \mathrm{g}$ of total RNA, using 50 pmol of each CCK-BR primer, or 25 pmol of each $B$-actin primer. Reverse transcription was carried out at $48^{\circ} \mathrm{C}$ for $1 \mathrm{~h}$, followed by $94^{\circ} \mathrm{C}$ for $2 \mathrm{~min}$. On duplicate samples, reverse transcriptase was omitted as a negative control. PCR was 40 cycles of $94^{\circ} \mathrm{C}$ for $45 \mathrm{sec}, 60^{\circ} \mathrm{C}$ for $90 \mathrm{sec}, 68^{\circ} \mathrm{C}$ for $2 \mathrm{~min}$, followed by a final cycle of $68^{\circ} \mathrm{C}$ for $7 \mathrm{~min}$. A second round of PCR was performed using the Taqbead hot start polymerase system (Promega), on $2 \mu 1$ of the primary reaction, under the same cycling conditions. Products were analysed by agarose gel electrophoresis.

\section{Results}

The specificity and sensitivity of immunostaining obtained using anti-GRE1 antibody labelled with Alexa-546 was confirmed by staining sections from a formalin-fixed paraffinembedded gastrinoma. Nuclear staining of the gastrinoma was obtained with both fluorescently labelled and unlabelled
anti-GRE1 antibody; this staining could be abolished by preabsorbance with epitope. This staining pattern has previously been described (27). $\mathrm{F}(\mathrm{ab})$ and $\mathrm{F}(\mathrm{ab})_{2}$ fragments of anti-GRE1 labelled with rhodamine gave the same staining pattern on this material; this staining could also be abolished by preabsorbance of the antibody with the epitope.

Uptake of RG-G7. Binding and internalisation of gastrin (RG-G7) was seen in AR42J, HepG2 and C170HM2 cells (Table I; Fig. 1a-c). Gastrin was taken up into the cytoplasm of these cancer cells. Binding was also seen in NIH3T3 cells stably transfected with gastrin receptor (Fig. 1d), but not in non-transfected NIH3T3. Fixed AR42J cells showing gastrin uptake were stained for gastrin receptor using Alexa-546 conjugated anti-GRE1 antibody, co-expression of gastrin and gastrin receptor was seen (Fig. 2). Gastrin receptor was detected on the membrane and within the cytoplasm of these cells.

Uptake of anti-GRE1 antibody. In the tumour cell lines AR42J, C170HM2 and HepG2, addition of anti-GRE1 antibody to live tumour cells resulted in binding and internalisation of the antibody into the cytoplasm and the nucleus of cells (Figs. 3 and 4). $\mathrm{F}(\mathrm{ab})$ and $\mathrm{F}(\mathrm{ab})_{2}$ fragments of anti-GRE1 antibody were also incubated with live cells from these tumour lines; uptake into the cytoplasm and the nucleus was seen. No uptake of rhodamine-conjugated irrelevant antibodies [rabbit anti-mouse antibody; rabbit $\operatorname{IgG}, \mathrm{F}(\mathrm{ab})_{2}$ fragment] by these cell lines was seen. Uptake of anti-GRE1 antibody was not seen in non-transfected NIH3T3 cells. In NIH3T3 cells transfected with human gastrin/CCK-B receptor, addition of anti-GRE1 antibody to live cells resulted in binding to the membrane of cells (Fig. 4). This pattern of uptake differed from that seen in the tumour cell lines in that binding was confined to the membrane whereas tumour cells also demonstrated translocation to the nucleus.

Detection of apoptosis. Cells which showed anti-GRE1 antibody uptake were also found to be positive for apoptosis (Fig. 5). This coincidence of uptake and apoptosis was seen in tumour cell lines, but not in NIH3T3 cell lines.

Immunoblotting. The results of Western blotting of whole cell lysates is shown in Fig. 6. Specific immunoreactive bands of 

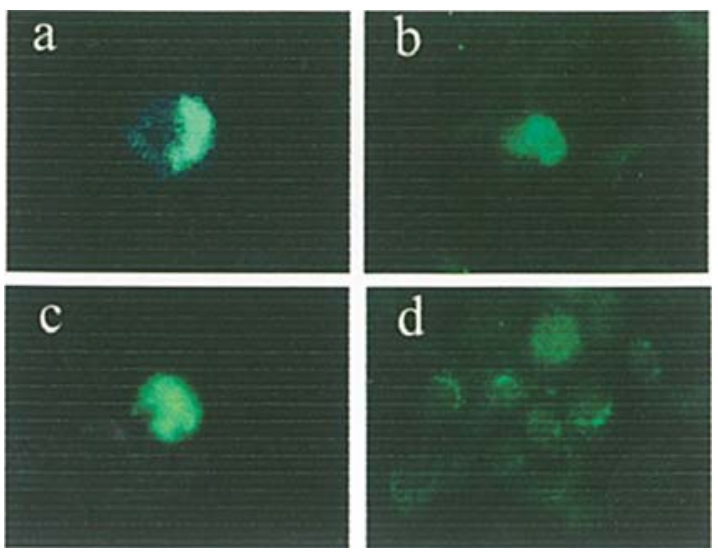

Figure 1. Fluorescently labelled gastrin (RG-G7) was added to (a) AR42J cells, (b) HepG2 cells, and (c) C170HM2 cells. Internalisation of gastrin was seen in all cell lines, as it was in NIH3T3 cells stably transfected with CCK-B/gastrin receptor (d). No binding or internalisation of RG-G7 was seen in non-transfected NIH3T3 cells.

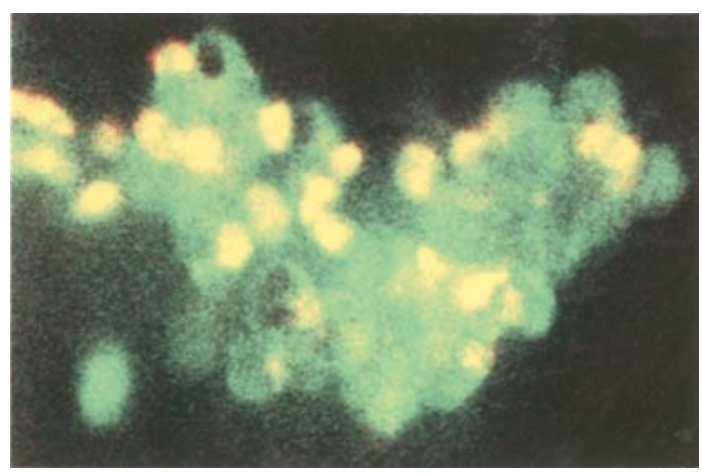

Figure 2. Confocal photomicrograph of AR42J cells incubated with RG-G7 (green), then fixed and stained with anti-CCK-B/gastrin receptor antibody, anti-GRE1 (red). Gastrin was taken up into the cytoplasm of these cells; colocalisation of gastrin and gastrin receptor (yellow) can be seen; gastrin receptor alone can be seen on the surface of one cell. Optical sectioning of the cells using the confocal microscope confirms gastrin is taken up into the cytoplasm but not the nucleus of cells.

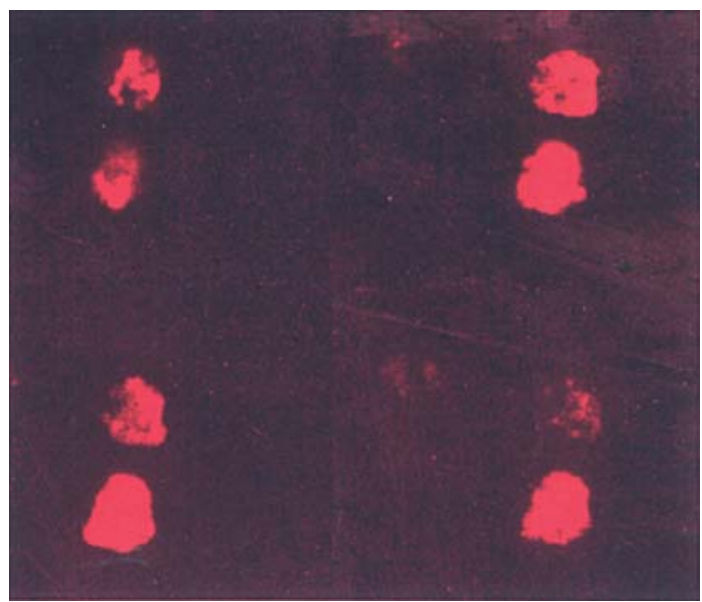

Figure 3. Live AR42J cells incubated with Alexa-546 labelled anti-CCK-BR antibody anti-GRE1 showed uptake of the antibody into the cell. Optical sectioning of the cell at $2-\mu \mathrm{m}$ intervals using confocal microscopy shows that antibody is taken up into the nucleus as well as the cytoplasm of the cell (confocal photomicrograph).

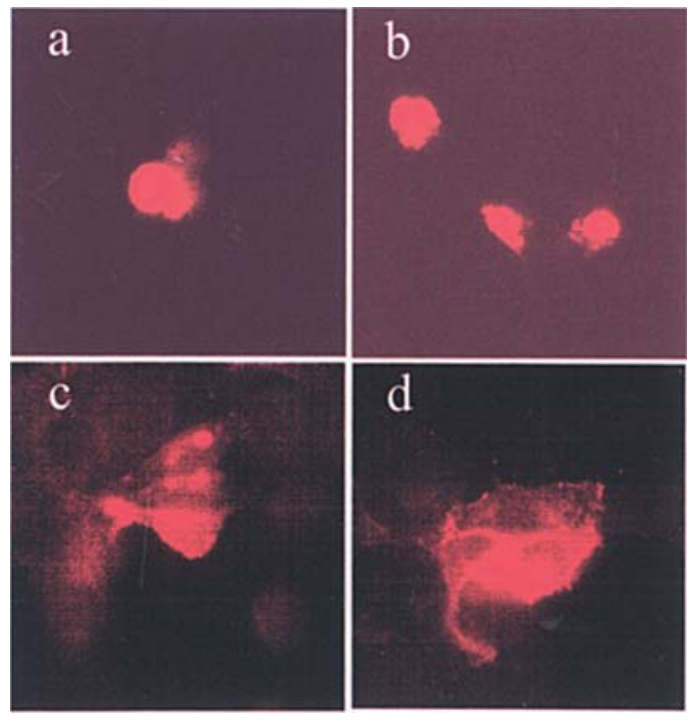

Figure 4. Anti-GRE1 antibody added to (a) C170HM2 cells and (b) HepG2 cells can be seen within the cytoplasm and the nucleus of cells. In contrast, NIH3T3 cells transfected with classical (c) and spliced variant (d) of CCK-B/ gastrin receptor show binding of anti-GRE1 antibody to the membrane of the cell, but no uptake into the nucleus (standard fluorescence photomicrograph; magnification, x660).
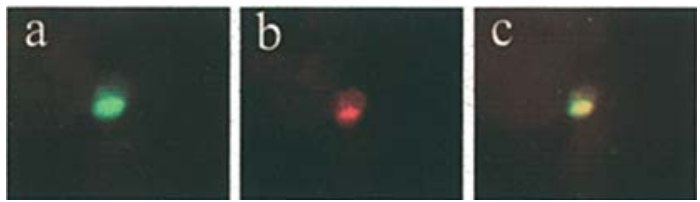

Figure 5. AR42J cell showing apoptosis, demonstrated by TUNEL assay (a) in a cell which has taken up anti-GRE1 antibody into the nucleus (b). Colocalisation can be seen (c) (fluorescence photomicrograph; x660). a

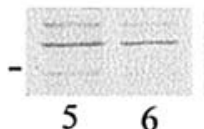

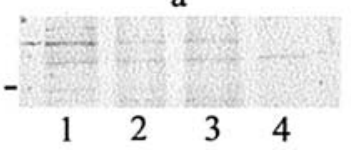

b

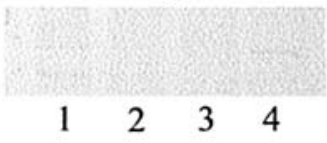

56
Figure 6. Western blotting on whole cell lysates from all cell lines. Blotting was performed using anti-GRE1 antibody (a), and on duplicate blots with antibody preabsorbed with epitope (b). AR42J cells (1) showed specific bands of $\mathrm{Mr}$ 241,000 184,000 and 124,000. NIH3T3 cells transfected with the spliced variant (2) and classical form (3) of the CCK-B/gastrin receptor showed specific bands of $M r$ 184,000 and 124,000. No specific bands were seen in non-transfected NIH3T3 cells (4). In C170HM2 (5) and HepG2 cells (6), specific bands of $\mathrm{Mr} 151,000$ and 112,000 were seen.

Mr 241,000, 184,000 and 124,000 were seen in AR42J cells. Bands of Mr 184,000 and 124,000 were also seen in NIH3T3 cells transfected with the classical and spliced variant of CCK-BR. In C170HM2 and HepG2 cell lines, specific bands were seen of $\mathrm{Mr} 151,000$ and 112,000. No specific immunoreactive bands were detected in non-transfected NIH3T3 cells. 


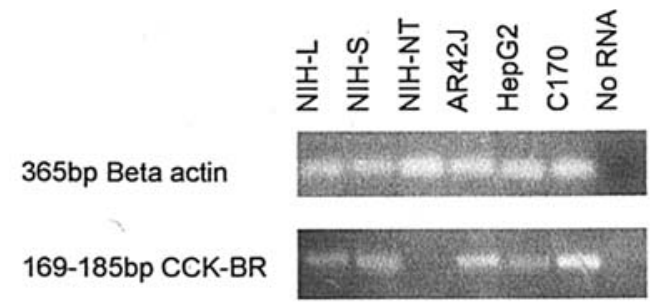

Figure 7. Gel showing products of RT-PCR for ß-actin (365 bp) and gastrin receptor (169-185 bp) mRNA. From left to right: NIH3T3 cells transfected with the spliced variant (NIH-L) and the classical form (NIH-S) of the CCK-B/gastrin receptor, were positive for $B$-actin mRNA, and CCK-B/ gastrin receptor mRNA. Non-transfected NIH3T3 cells were positive for B-actin mRNA, confirming successful extraction and amplification of mRNA, but negative for CCK-B/gastrin receptor mRNA. AR42J, HepG2 and C170HM2 cell lines were all positive for both $\beta$-actin mRNA, and CCK$\mathrm{B} /$ gastrin receptor mRNA. No amplification was seen in the control without RNA.

Table II. RT-PCR for B-actin and gastrin receptor mRNA on cell lines.

\begin{tabular}{lcc}
\hline Cell line & $\begin{array}{c}\text { B-actin } \\
\text { amplification }\end{array}$ & $\begin{array}{c}\text { Gastrin receptor } \\
\text { amplification }\end{array}$ \\
\hline
\end{tabular}

\begin{tabular}{lll}
\hline $\begin{array}{l}\text { NIH3T3 transfected with } \\
\text { gastrin receptor } \\
\text { (spliced variant) }\end{array}$ & + & + \\
$\begin{array}{l}\text { NIH3T3 transfected with } \\
\text { gastrin receptor (classical) }\end{array}$ & + & + \\
NIH3T3 non-transfected & + & - \\
AR42J & + & + \\
HepG2 & + & + \\
C170HM2 & + & + \\
\hline
\end{tabular}

Detection of $C C K-B /$ gastrin receptor $m R N A$. RT-PCR performed on all cell lines confirmed the expression of CCK-B/gastrin receptor mRNA in AR42J, C170HM2, HepG2 and NIH3T3 cells transfected with the classical and spliced variant form of the gastrin receptor gene. Gastrin receptor mRNA was not detected in non-transfected NIH3T3 cells. All cell lines were positive for $B$-actin mRNA, confirming successful extraction and amplification of mRNA (Table II; Fig. 7). No amplification was seen in duplicates without reverse transcriptase.

\section{Discussion}

This series of experiments has shown the internalisation of anti-CCK-B/gastrin receptor into the nucleus of live cancer cell lines of colonic, pancreatic and hepatic origin. Internalisation of the gastrin analogue RG-G7 and anti-gastrin receptor antibody was seen only in cell lines expressing CCK-B/gastrin receptor mRNA, including NIH3T3 cells transfected with classical and truncated isomers of human CCK-B/gastrin receptor. In control experiments no internalisation was seen in non-transfected NIH3T3 cells, i.e. not expressing CCKBR. No uptake of irrelevant antibodies, added under identical conditions, was seen in any of the cell lines.

Confocal microscopy showed that anti-GRE1 antibody is internalised by tumour cells and can be detected within the cytoplasm and the nucleus of cells. Nuclear uptake of the antibody was seen in the pancreatic, colonic and hepatic cancer cell lines. This translocation of anti-GRE1 antibody to the nucleus of tumour cells is interesting in the light of previous observations using immunohistochemistry in which nuclear expression of the CCK-B receptor was seen in human resection specimens of hepatocellular carcinoma, pancreatic carcinoma, and gastric carcinoid $(27,28,38)$. The internalisation of antiGRE1 antibody demonstrated in this study is specific; it is not mediated via the $\mathrm{Fc}$ receptor as $\mathrm{F}(\mathrm{ab})$ fragments of antiGRE1 antibody were internalised in a similar way, and no internalisation of irrelevant antibodies by these cell lines was detected under identical conditions. Most interestingly, a coincidence of nuclear uptake and apoptosis was seen in a high percentage of tumour cells; the relevance of this needs to be further investigated. In contrast to the nuclear uptake of anti-CCK-BR antibody, labelled peptide was taken up only into the cytoplasm of cells expressing CCK-BR.

A different pattern of uptake/binding of RG-G7 and GRE1 antibody was seen in the transfected NIH3T3 cells compared to the tumour cell lines. This binding was also specific as it was not seen in non-transfected NIH3T3 cells not expressing CCK-B/gastrin receptor mRNA (negative control). In cells transfected with the classical and spliced variant of CCK-BR (34), GRE1 antibody appeared to bind to the membrane, and was not translocated to the nucleus, as in the tumour cell lines. Similarly, the short gastrin RG-G7 bound only to the membrane of transfected NIH3T3 cells and was not taken up into the cytoplasm. This may represent some inherent difference between naturally expressed and cloned CCK-BR, or it may be a demonstration of differential isomer expression of the receptor in tumours. Watson et al (18) have reported that NIH3T3 cells transfected with classical CCK-BR only express a plasma membrane bound isomer of CCK-BR of Mr 70,000, whereas C170HM2 cells (which showed nuclear uptake of anti-GRE1 in these experiments) showed expression

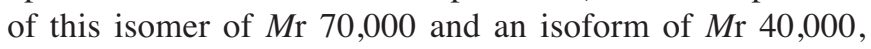
which was only found in an intracellular location. This could also reflect a difference in autocrine production of gastrin and its precursors. NIH3T3 cells do not express progastrin, glycine extended gastrin or amidated gastrin (18), whereas AR42J cells (39), and C170HM2 cells express these precursor forms of gastrin (18). Whilst HepG2 cells have not been tested for expression of gastrin precursor forms, studies in hepatocellular carcinoma have shown that many of these tumours express progastrin and glycine extended gastrin (27). Progastrin and glycine extended gastrin are thought to have their own distinct receptor(s), but may have some effect through CCK-BR (isomers) (18).

Western blotting carried out on these cell lines using antiGRE1 antibody gave specific bands in all cell lines positive for CCK-BR mRNA, but not in non-transfected NIH3T3 cells, negative for CCK-BR mRNA by RT-PCR. The bands were of $\mathrm{Mr} 241,000,184,000$ and 124,000 in AR42J cells; of $\mathrm{Mr}$ 184,000 and 124,000 in transfected NIH3T3 cells, and of 
Mr 151,000 and 112,000 in C170HM2 and HepG2 cells. This variation in the weight of CCK-BR is most likely because CCK-BR is known to exist as several isoforms $(18,40)$. Early studies on gastrin binding proteins in guinea pigs reported molecular weights varying from $M r$ 33,000 to 250,000 (41); the degree of glycosylation of the receptor can also affect molecular weight (42). Ito et al (34) have described a splice variant of CCK-BR which differs from classical CCK-BR by a 5 amino acid insertion; Miyake et al (43) and McWilliams et al (19) have detected a truncated isoform of the receptor in several tumour cell lines. These differences may reflect a variation in technique, as blotting was performed on whole cell lysates, whereas other studies analysed subcellular membrane fractions (18); the larger molecular weight proteins detected here may represent an undegraded complex of CCK-BR.

Whilst other studies have reported recycling of CCK-BR to the plasma membrane after release of gastrin into lysosomes (30), translocation of $\mathrm{G}$ protein coupled receptors to the nucleus is not unique. Insulin (44), IL-1 (45) and epidermal growth factor receptors (46) are all reported to translocate to the nucleus; indeed, translocation of anti-epidermal growth factor receptor antibody to the nucleus of cells expressing surface receptor has also been described (47). It has been suggested that chromatin binding of these and other growth factors, including basic fibroblast growth factor, nerve growth factor, and platelet derived growth factor, may be an important step in growth factor induced gene activation $(46,48)$. We have previously described uptake of anti-GRE1 antibody and binding to chromatin in AR42J cells by immuno-electron microscopy (29); this may represent a mechanism by which gastrin receptor mediates the trophic effect of gastrin.

Nuclear translocation of the antibody/receptor complex may have important therapeutic implications. Animal studies (49) have shown that anti-GRE1 antibody has an inhibitory effect on growth of liver metastases of colon cancer in mice. A higher uptake of antibody was detected in tumour versus background liver, and a decreased tumour burden was seen in mice treated with this (unconjugated) antibody. Apoptosis was seen within the treated tumours, and a slight increase in necrosis over untreated animals was seen. Our observations of a coincidence of apoptosis in cells taking up anti-GRE1 antibody into the nucleus suggest that nuclear translocation of the antibody could be the mechanism of this observed effect.

The anti-CCK-BR antibody could be useful in the diagnosis and treatment of CCK-B expressing tumours. Likewise, the specific uptake of the RG-G7 gastrin peptide by cells expressing gastrin receptor suggests that this may also be useful for imaging and therapy of tumours overexpressing CCK-BR $(50,51)$. Further study needs to be carried out to examine whether the observed nuclear uptake of anti-GRE1 antibody is a general function of tumour as opposed to nontumour cells. Nuclear uptake has been reported with profile targeted therapy for example with the ${ }^{111}$ Indium-labelled somatostatin analogue, Octreotide; this uptake into the nucleus can give an unexpected increase in toxicity to tumour cells even using the low activity ${ }^{111}$ Indium isotope (52). Strategies concentrating radioactivity within the nucleus using anti-GRE1 antibody may achieve similar results, and potentiate the effect observed with unlabelled antibody (49). Peptide targeting of CCK-BR expressing tumours has been utilised for both imaging and therapy (53-57), and the potential of agents targeting regulatory peptide receptors overexpressed in numerous human cancers is increasingly recognised $(51,58)$. Gunther et al have observed that in AR42J cells, agonist exposure upregulates CCK-BR gene expression; peptide targeted therapy, using molecules such as RG-G7, could be combined with antiCCK-BR antibody therapy to increase therapeutic effect (59). Targeting the CCK-B/gastrin receptor by anti-CCK-B/ gastrin receptor antibody or gastrin peptide represents a novel approach which may be a useful adjuvant to treatment strategies for a number of cancers.

\section{Acknowledgements}

This study was funded by a research grant from the Aphton Corporation. We wish to thank Dr Chris Thrasivoulou for his help and advice with the confocal microscopy. Professor Matsui of Kobe University, Japan, kindly provided the transfected NIH3T3 cells.

\section{References}

1. Edkins JS: The chemical mechanism of gastric secretion. J Physiol 34: 133-144, 1906.

2. Waldum HL, Brenna E, Kleveland PM and Sandvik AK: Gastrin - physiological and pathophysiological consequences. Dig Dis 13: 25-38, 1995.

3. Ekundayo AA, Lee CY and Goodlad RA: Gastrin and the growth of the gastrointestinal tract. Gut 2: 203-208, 1995.

4. Townsend CM, Beauchamp RD, Singh P and Thompson JC: Growth factors and intestinal neoplasms. Am J Surg 155: 526-536, 1988.

5. Smith AM and Watson SA: Gastrin and colorectal cancer. Aliment Pharmacol Ther 14: 1231-1247, 2000.

6. Watson S, Durrant L and Morris D: Gastrin growth enhancing effects on human gastric and colonic tumour cells. Br J Cancer 59: 554-558, 1989 .

7. Singh P, Walker JP, Townsend CM and Thompson JC: Role of gastrin and gastrin receptors on the growth of a transplantable mouse colon carcinoma (MC-26) in BALBc mice. Cancer Res 46: 1612-1616, 1987.

8. Rehfeld IF, Bardram L and Histed L: Gastrin in human bronchogenic carcinomas: constant expression but variable processing of progastrin. Cancer Res 49: 2840-2843, 1989.

9. Blackmore M, Doherty E, Manning IF and Hirst BH: Autocrine growth stimulation of human Wilms tumour G401 cells by a gastrin-like peptide. Int J Cancer 57: 385-391, 1994.

10. Dockray GJ, Varro A and Dimaline R: Gastric endocrine cells: gene expression, processing and targeting of active products. Physiol Rev 76: 767-798, 1996.

11. Kopin AS, Lee YM, McBride EW, et al: Expression cloning and characterization of the canine parietal cell gastrin receptor. Proc Natl Acad Sci USA 89: 3605-3609, 1992.

12. Sankaran H, Goldfine ID, Deveney CW, Wong KY and Williams JA: Binding of cholecystokinin to high affinity receptors on isolated rat pancreatic acini. J Biol Chem 255: 1849-1853, 1980.

13. Innis RB and Snyder SH: Distinct cholecystokinin receptors in brain and pancreas. Proc Natl Acad Sci USA 77: 6917-6921, 1980.

14. Pisegna JR, de Weerth A, Huppi K and Wank SA: Molecular cloning of the human brain and gastric cholecystokinin receptor: structure, functional expression and chromosomal localization. Biochem Biophys Res Commun 30: 96-303, 1992.

15. Lee YM, Beinborn M, McBride EW, Lu M, Kolakowski LF Jr and Kopin AS: The human brain cholecystokinin-B/gastrin receptor. Cloning and characterization. J Biol Chem 268: 8164-8169, 1993.

16. Wank SA, Pisegna JR and de Weerth A: Brain and gastrointestinal cholecystokinin receptor family: structure and functional expression. Proc Natl Acad Sci USA 89: 8691-8695, 1992.

17. Baldwin GS and Shulkes A: Gastrin, gastrin receptors and colorectal carcinoma. Gut 42: 581-584, 1998. 
18. Watson SA, Clarke PA, Smith AM, et al: Expression of CCK-B/ gastrin receptor isoforms in gastro-intestinal tumours. Int $\mathrm{J}$ Cancer 77: 572-577, 1998.

19. McWilliams DF, Watson SA, Crosbee DM, Michaeli D and Seth R: Coexpression of gastrin and gastrin receptors (CCK-B and delta CCK-B) in gastrointestinal tumour cell lines. Gut 42: 795-798, 1998

20. Okada N, Kubota A, Imamura T, et al: Evaluation of cholecystokinin, gastrin, CCK-A receptor, and CCK-B/gastrin receptor gene expressions in gastric cancer. Cancer Lett 106: 257-262, 1996.

21. Frucht H, Gazdar AF, Park JA, Oie H and Jensen RT: Characterization of functional receptors for gastrointestinal hormones on human colon cancer cells. Cancer Res 52: 1114-1122, 1992.

22. Caplin ME, Millson C, Michaeli D, Watson SA and Dhillon AP: Serum gastrin levels and identification of CCK-B/gastrin receptor following partial hepatectomy for liver tumours in man. Gastroenterology 110: A1162, 1996.

23. Matsumori Y, Katakami N, Ito M, et al: Cholecystokinin-B/ gastrin receptor: a novel molecular probe for human small cell lung cancer. Cancer Res 55: 276-279, 1995.

24. Lignon MF, Bernad N and Martinez J: Pharmacological characterization of type B cholecystokinin binding sites on the human JURKAT T lymphocyte cell line. Mol Pharmacol 39: 615-620, 1991

25. Iwata N, Murayama T, Matsumori Y, et al: Autocrine loop through cholecystokinin-B/gastrin receptors involved in growth of human leukemia cells. Blood 88: 2683-2689, 1996.

26. Hur K, Kwak MK, Lee HJ, Park do J, Lee HK, Lee HS, Kim WH, Michaeli D and Yang HK: Expression of gastrin and its receptor in human gastric cancer tissues. J Cancer Res Clin Oncol 132: 85-91, 2006.

27. Caplin M, Khan K, Savage K, et al: Expression and processing of gastrin in hepatocellular carcinoma, fibrolamellar carcinoma and cholangiocarcinoma. J Hepatol 30: 519-526, 1999.

28. Caplin M, Savage K, Khan K, et al: Expression and processing of gastrin in pancreatic adenocarcinoma. Br J Surg 87: 1035-1040, 2000.

29. Caplin ME, Clarke P, Grimes S, et al: Demonstration of new sites of expression of the CCK-B/gastrin receptor in pancreatic acinar AR42J cells using immunoelectron microscopy. Regul Pept 84: 81-89, 1999.

30. Tarasova NI, Wank SA, Hudson EA, et al: Endocytosis of gastrin in cancer cells expressing gastrin/CCK-B receptor. Cell Tissue Res 287: 325-333, 1997.

31. Seva C, De Vries L, Scemama JL, et al: Gastrin modulates growth of a rat acinar pancreatic cell line: receptor analysis and signal transduction. Digestion 46: 166-169, 1990.

32. Schwartz AL, Fridovich SE, Knowles BB and Lodish HF: Characterization of the asialoglycoprotein receptor in a continuous hepatoma line. J Biol Chem 256: 8878-8881, 1981.

33. Watson SA, Morris TM, Crosbee DM and Hardcastle JD: A hepatic invasive human colorectal xenograft model. Eur J Cancer 29A: 1740-1745, 1993.

34. Ito M, Iwata N, Taniguchi T, Murayama T, Chihara $\mathrm{K}$ and Matsui T: Functional characterisation of two cholecystokinin-B/ gastrin receptor isoforms: a preferential splice donor site in the human receptor gene. Cell Growth Differ 5: 1127-1135, 1994.

35. Czerwinski G, Wank SA, Tarasova NI, Hudson EA, Resau JH and Michejda CJ: Synthesis and properties of three fluorescent derivatives of gastrin. Lett Pept Sci 1: 235-242, 1995.

36. Panchuk-Voloshina N, Haugland RP, Bishop-Stewart J, et al: Alexa dyes, a series of new fluorescent dyes that yield exceptionally bright, photostable conjugates. J Histochem Cytochem 47: 1179-1188, 1999.

37. Harlow E and Lane D: Labelling antibodies. In: Antibodies: A Laboratory Manual. Cold Spring Harbour Laboratories, New York, pp319-358, 1988.

38. Smith AM, Watson SA, Caplin M, et al: Gastric carcinoid expresses the gastrin autocrine pathway. Br J Surg 85: 1285-1289, 1998.

39. Seva C, Dickinson CJ and Yamada T: Growth promoting effects of glycine-extended progastrin. Science 265: 410-412, 1994.
40. Baldwin GS: Gastrin receptor structure. In: Gastrin. Walsh JH (ed). Raven, New York, pp195-203, 1993.

41. Narayan S, Chicone L and Singh P: Characterisation of gastrin binding to colonic mucosal membranes of guinea pigs. Mol Cell Biochem 112: 163-171, 1992.

42. Le Meuth V, Philouze-Rome V, Hueron-Luron IL, et al: Differential expression of A- and B- subtypes of cholecystokinin/ gastrin receptors in the developing calf pancreas. Endocrinology 133: 1182-1191, 1993.

43. Miyake A: A truncated isoform of human CCK-B/gastrin receptor generated by alternative usage of a novel exon. Biochem Biophys Res Commun 208: 230-237, 1995.

44. Podlecki DA, Smith RM, Kao M, et al: Nuclear translocation of the insulin receptor. A possible mediator of insulin's long term effects. J Biol Chem 262: 3362-3368, 1987.

45. Curtis BM, Widmer MB, deRoos P and Qwarnstrom EE: IL-1 and its receptor are translocated to the nucleus. J Immunol 144: 1295-1303, 1990.

46. Holt SJ, Alexander P, Inman CB and Davies DE: Epidermal growth factor induced tyrosine phosphorylation of nuclear proteins associated with translocation of epidermal growth factor receptor into the nucleus. Biochem Pharmacol 47: 117-126, 1994.

47. Rakowicz-Szulczynska E, Otwiaska D, Rodeck U and Koprowski H: Epidermal growth factor (EGF) and monoclonal antibody to cell surface EGF receptor bind to the same chromatin receptor. Arch Biochem Biophys 268: 456-464, 1989.

48. Rakowicz-Szulczynska EM, Rodeck U, Herlyn M and Koprowski H: Chromatin binding of epidermal growth factor, nerve growth factor, and platelet-derived growth factor in cells bearing the appropriate surface receptors. Proc Natl Acad Sci USA 83: 3728-3732, 1986.

49. Watson SA, Clarke PA, Morris TM and Caplin ME: Antiserum raised against an epitope of the cholecystokinin $\mathrm{B} /$ gastrin receptor inhibits hepatic invasion of a human colon tumour. Cancer Res 60: 5902-5907, 2000.

50. Krenning EP, Kwekkeboom DJ, Valkema R, Pauwels S, Kvols LK and De Jong M: Peptide receptor radionuclide therapy. Ann NY Acad Sci 1014: 234-245, 2004.

51. Reubi JC, Macke HR and Krenning EP: Candidates for peptide receptor radiotherapy today and in the future. J Nucl Med 46 (suppl 1): 67S-75S, 2005

52. Tiensu Janson E, Westlin J, Ohrvall U, Oberg K and Lukinius A: Nuclear localization of ${ }^{111}$ In after intravenous injection of [111 InDTPA-D-Phe ${ }^{1}$-Octreotide in patients with neuroendocrine tumors. J Nucl Med 41: 1514-1518, 2000.

53. Behr TM, Behe M, Angerstein C, et al: Choecystokinin-B/ gastrin receptor binding peptides: preclinical development and evaluation of their diagnostic and therapeutic potential. Clin Cancer Res 5 (suppl 10): 3124s-3138s, 1999.

54. Behr TM, Jenner N, Behe M, et al: Radiolabelled peptides for targeting cholecystokinin-B/gastrin receptor-expressing tumours. J Nucl Med 40: 1029-1044, 1999.

55. Behe M, Becker W, Gotthardt M, Angerstein C and Behr TM Improved kinetic stability of DTPA-dGlu as compared with conventional monofunctional DTPA in chelating indium and yttrium: preclinical and initial clinical evaluation of radiometal labelled minigastrin derivatives. Eur J Nucl Med Mol Imaging 30: 1140-1146, 2003

56. Gotthardt M, Behe MP, Alfke $\mathrm{H}$ and Behr TM: Imaging lung tumors with peptide-based radioligands. Clin Lung Cancer 5: 119-124, 2003.

57. Nock BA, Maina T, Behe M, et al: CCK-2/gastrin receptortargeted tumor imaging with $(99 \mathrm{~m})$ Tc-labeled minigastrin analogs. J Nucl Med 46: 1727-1736, 2005.

58. Stubbs M, Khan K, Wickremasinghe RG, Ganeshaguru K and Caplin ME: CCK2 gastrin receptor as a potential target for therapy in leukaemia cell lines. Oncol Rep 14: 1055-1058, 2005.

59. Gunther R, Carstens OC, Schmidt WE and Folsch UR: Transient agonist-induced regulation of the cholecystokinin-A and cholecystokinin-B receptor mRNA levels in rat pancreatic acinar AR42J cells. Pancreatology 3: 47-54, 2003. 